\title{
Arenethiolatocopper(I) Complexes as Homogeneous Catalysts for Michael Addition Reactions
}

\author{
Mayra van Klaveren, François Lambert, Desiree J. F. M. Eijkelkamp, David M. Grove and \\ Gerard van Koten*
}

Debye Institute, Department of Metal-Mediated Synthesis, Utrecht University,

Pactualaan 8, 3584 CH Utrocht, The Nethertands

\begin{abstract}
Abstrect: Arenethiolatocopper(I) complexes are shown to be efficient homogeneous catalysts in Michael addition reactions of several Grignard reagents to acyclic enones; the addition products are formed with excellent chemoselectivity (>99\%) and good enantioselectivity ( $76 \%$ e.e.).
\end{abstract}

An important aspect in contemporary organic chemistry is chemoselective C-C bund formation with high enantioselectivity. This goal has been achieved in Michael addition and cross-coupling reactions that are under substrate control (e.g. in prostaglandin synthesis) through the use of an organometallic reagent (RMgX or RLi) combined with stoichiometric amounts of various copper(I) salts (e.g. CuCl and $\mathrm{CuCN}){ }^{1}$ Only a few examples have been reported in which these reactions are successful when catalytic amounts of a copper(I) salt are used. ${ }^{2}$

We are now developing new types of arenethiolatocopper(I) catalysts (CuSAr, 3a-d, Scheme 1) for 1,4addition reactions with enones ${ }^{3}$ and 1,6 -addition reactions with enyn esters. ${ }^{4}$ In these reactions the ortho-amino arenethiolate anion has excellent properties as a non-transferable group for obtaining high chemo- and regioselectivity. Recently, in collaboration with Backvall et al., we have demonstrated that the use of the arenethiolatocopper(I) catalysts 3 can also afford high chemo- and regioselectivity in cross-coupling reactions. 5

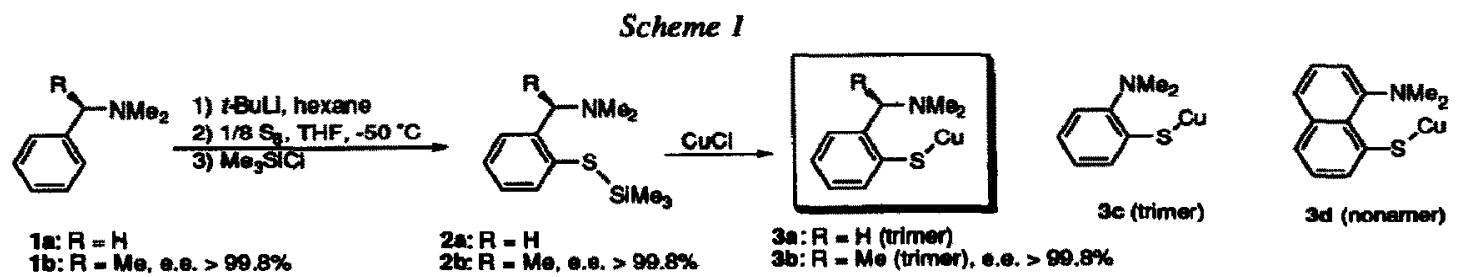

We now show the broad applicability of catalysts $3 \mathrm{a}-\mathbf{d}$ in Michael addition reactions of Grignard reagents to acyclic enones. Our understanding of this catalytic system has been increased by varying not only the experimental paraneters (Section I), but also the steric and electronic properties of the enone (Section II).

I) Studies of the experimental parameters.

Arenethiolatocopper(I) complexes 3 have been employed as catalysts for the 1,4-addition reaction of a Grignard reagent (RMgI) to 4-phenyl-3-buten-2-one 4 (that affords 4-phenyl-3-pentan-2-one 5 after hydrolysis) and this system was used to investigate the influence of (i) the addition method, (ii) the amount of chiral CuSAr $3 \mathrm{~b}$, (iii) the solvent and the presence of additives, (iv) the Grignard reagent and ( $v$ ) the exact type of catalyst 
(3a-d). The results are collected in Table I. Chiral complex $3 b(R, R, R)$ was prepared as described previously (Scheme 1), 3b starting from $1 \mathrm{~b}$ with an e.e. of $>99.8 \%$. The same syntheric strategy (Scheme 1) was used to prepare $3 \mathrm{a}$ (trimer), 3c (trimer) and $3 \mathrm{~d}$ (nonamer). ${ }^{3 \mathrm{e}}$

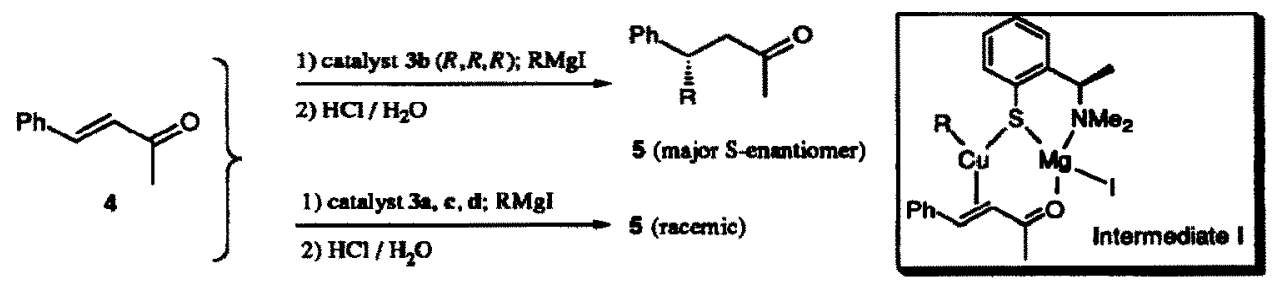

Table L. Influence of experimental parameters in the 1,4-addition of RMgl to 4 using CuSAr catalysts in Eh $\mathrm{O}$ at 0 C.*

\begin{tabular}{|c|c|c|c|c|c|c|}
\hline \multirow[t]{2}{*}{ Entry } & \multirow[t]{2}{*}{$\mathbf{R}$} & \multirow{2}{*}{$\frac{\text { Catalyst }^{b}}{(\mathrm{~mol} \%)}$} & \multirow{2}{*}{ Conditions } & \multirow{2}{*}{$\frac{\text { s: Yield }}{(\%)}$} & \multirow{2}{*}{$\frac{(\text { Selectivity })^{8}}{(\%)}$} & \multirow{2}{*}{$\frac{\text { E.e. }}{(\%)}$} \\
\hline & & & & & & \\
\hline 1. & $\mathrm{Me}$ & $3 b(9)$ & [A, none] & 41 & (43) & 45 \\
\hline 2. & $n$ & $\mathbf{3 b}(9)$ & {$[\mathbf{B}$, none $]$} & 78 & (78) & 0 \\
\hline 3. & $*$ & $\mathbf{3 b}(9)$ & [C, none] & 97 & $(97)$ & 76 \\
\hline 4. & $"$ & $3 b(4)$ & [C, none] & 83 & (83) & 70 \\
\hline 5. & " & $\mathbf{3 b}(9)$ & {$[\mathrm{C}, \text { none }]^{\mathrm{a}}$} & 86 & (86) & 0 \\
\hline 6. & " & $3 \mathbf{b}(9)$ & {$\left[\mathrm{C}, \mathrm{SiMe}_{3} \mathrm{Cl}\right]$} & 65 & (65) & 70 \\
\hline 7. & $"$ & $3 \mathbf{b}(9)$ & {$\left[\mathrm{C}, \mathrm{SiMe}_{3} \mathrm{Cl}+\mathrm{HMPA}\right]$} & 88 & (14) & 14 \\
\hline 8. & $*$ & $3 b(9)$ & {$\left[\mathrm{C}, \mathrm{BF}_{3} \cdot \mathrm{OEt}_{2}\right]$} & 16 & (29) & $\mathbf{0}$ \\
\hline 9. & $\mathbf{n} \cdot \mathbf{B u}$ & $3 b(9)$ & {$[\mathrm{C}$, none] } & $>95$ & $(>95)$ & $45^{i}$ \\
\hline 10. & $i-\mathbf{P r}$ & $3 b(9)$ & {$[\mathrm{C}$, none] } & $>95$ & $(>95)$ & 10 \\
\hline 11 & $\mathrm{Me}$ & $3 \mathbf{a}(9)$ & {$[\mathrm{C}$, none $]$} & 95 & (95) & - \\
\hline 12. & 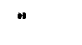 & $3 c(9)$ & {$[\mathrm{C}$, nonee $]$} & 93 & (93) & - \\
\hline 13. & 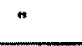 & $3 d(9)$ & [C, none] & 93 & (93) & - \\
\hline
\end{tabular}

a) Except for entry 5 which was carried out in THF. b) Amount based on monomeric CuSAr units; $(R, R, R)$ enantioner of trimeric 3b. c) See text. d) Added to 4 before use (1 equiv,), e) Conversion is quantative except for entries 1 (95\%), 8 (56\%) and 10 (98 \%). Yield determined by capillary GC with phenylacetone as internal standard. $f$ ) The only cher side products are a result of enolate formation. ${ }^{6} \mathrm{~g}$ ) Selectivity $=$ Yield $/$ Conversion. h) E.e. of 5 ( $(S)$-enantiomer) determined by capillary $G C$ with a chiral column. i) Determined by ${ }^{13} \mathrm{C}$ NMR of the corresponding ketal with $(R, R)-(-)-2,3-$ butanediol.

(i) Addition method: To obtain the best possible chemo- and enantioselectivity, three addition methods have been investigated (A, B and $C$ ) for our system using MeMgl as reagent and 9 mol\% of chiral CuSAr $3 b$ (based on monomeric copper units). Addition method $\mathrm{A}$, involving the addition of $\mathrm{MeMgI}$ to an ethereal solution of 4 and $3 b$ (entry 1 ) results in a $41 \%$ yield of 5 with an e.e. of $45 \%$ ((S)-enantiomer). In addition method B, where 4 is added to an ethereal solution of MeMgI with 3b, a 78\% yield of 5 with an e.e. of $0 \%$ is obtained (entry 2). The best addition method is method $C$, which involves the controlled, simultaneous addition of solutions of $\mathrm{MeMgI}$ and of 4 (at equal concentration) to catalyst $3 \mathrm{~b}$ in $\mathrm{Et}_{2} \mathrm{O}$ (entry 3). This results in $100 \%$ conversion of 4 with a $97 \%$ yield of 5 that has an e.e. of $76 \%$. Variation of the other experimental parameters (ii-v) in this section (I) all employ addition method $\mathrm{C}$.

(ii) Amount of chiral CuSAr 3b: The amount of 3b in the reaction of 4 with MeMgI significantly influences the chemo- and enantioselectivity: with 9 mol\% of 3b the 1,4-product 5 is obtained in $97 \%$ yield with $76 \%$ e.e. (entry 3 ), but with 4 mol\% of $3 b$ it is obtained in only $83 \%$ yield with an e.e. of $70 \%$ (entry 4 ). 
(iii) Solvent and additives: The chemo- and enantioselectivity of the reaction of MeMgI with 4, using 9 mol\% of 3b, is dependent on both the solvent and the presence of various additives. With a strongly polar solvent (e.g. THF) the e.e. of product 5 is $0 \%$ (cf. entries 3 and 5). Using additives in the same reaction in $\mathrm{Et}_{2} \mathrm{O}$, e.g. $\mathrm{SiMe}_{3} \mathrm{Cl}$ (entry 6), $\mathrm{SiMe}_{3} \mathrm{Cl}$ with $\mathrm{HMPA}$ (entry 7) or the strong Lewis acid $\mathrm{BF}_{3} \cdot \mathrm{OE}_{2}$ (entry 8), results in a lower chemo- and enantioselectivity. These results contrast with literature reports, ${ }^{2 \mathrm{~b}, 7}$ in which polar additives increase both the chemoselectivity and enantioselectivity of organocuprate reactions.

(iv) Grignand reagent: The scope of these Michael addition reactions has been extended to other Grignard reagents (n-BuMgI and $i$-PrMgI) using the optimal parameters found for MeMgI (method $\mathrm{C}, \mathrm{Et}_{2} \mathrm{O}, \mathrm{O}^{\circ} \mathrm{C}, 9$ mol\% $3 b$ ). Using $n$-BuMgI and 4 , the corresponding product 5 is formed with more than $95 \%$ selectivity with an e.e. of $45 \%$ (entry 9). By using $i$-PrMgI in the same reaction 5 is obtained with an e.e. of $10 \%$ (entry 10).

(v) Copper(m catalyst: The non-transferable amino arenethiolate anions in complexes 3a-d differ with respect to the donor abilities of their N,S-binding sites as well as in the flexibility of the hydrocarbon chain connecting the $\mathrm{N}$ - and S-donor atoms. However, despite these differences, these catalysts 3 (entries 11 (3a), 3 (3b), 12 (3c) and 13 (3d)) afford a high chemoselectivity in the Michael addition reaction of MeMgl to 4.

Our results described above for the high chemo- and enantioselectivity of these 1,4-addition reactions with CuSAr catalysts 3 can be explained by the formation of key intermediate $I^{3 c, d}$ (the "active" site in what may be a larger aggregate). In intermediate $\mathrm{I}$ the enone anchors to the $\mathrm{Cu}-\mathrm{Mg}$ arenethiolate unit in a bidentate fashion with the double bond coordinating to copper ${ }^{8}$ and oxygen coordinating to $\mathbf{M g}$. In this way the $\mathrm{R}$ of $\mathrm{RMgX}$ is directed selectively to the 4-position of the enone. The formation of $\mathrm{I}$ can also be seen as a formal addition of the $\mathrm{Mg}-\mathrm{C}$ bond over the $\mathrm{Cu}-\mathrm{S}$ (arene) bond. The results with additives (entries 6,7 and 8) suggest that I can exist in the presence of magnesium enolates but that additives, e.g. HMPA, can disrupt the Cu-S-Mg motif. Current studies to further directly elucidate the nature of I include solution EXAFS measurements.

II) Studies of the electronic and steric properties of the enone.

Extra insights into the bonding scheme of $I$ have been obtained by studying the reaction of MeMgI with various enones that have (i) different para substituents $X$ on the aromatic ring and (ii) different substituents $R^{l}$ on the carbonyl group. The results, using the optimal experimental parameters found for the reaction of 4 with MeMgI (method C, $\mathrm{Et}_{2} \mathrm{O}, \mathrm{O}^{\circ} \mathrm{C}, 9^{\mathrm{mol}} \%$ of $3 \mathrm{~b}$ ), are collected in Table II.
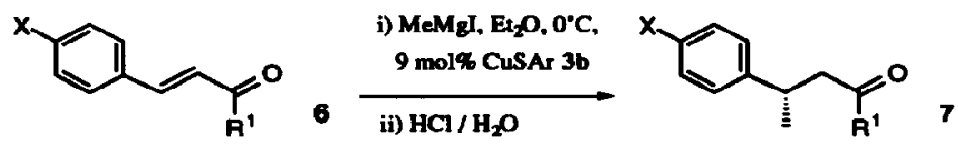

Table II Variation of $X$ and $R^{1}$ of the enone 6 in the 1,4-addition reaction with MeMgI using 9 mol\% of $3 b$.

\begin{tabular}{|c|c|c|c|c|}
\hline Entry & $\mathbf{x}$ & $\mathbf{R}^{\mathbf{1}}$ & Yielda,b of $7(\%)$ & E.e. ${ }^{c}$ of 7 (\%) \\
\hline 1. & CN & Me & 20 & 13 \\
\hline 2. & Cl & $\mathbf{M e}$ & $>99$ & 69 \\
\hline 3. & $\mathbf{H}$ & Me & 97 & 76 \\
\hline 4. & Me & Me & $>99$ & 64 \\
\hline 5. & OMe & Me & $>99$ & $56^{d}$ \\
\hline 6. & $\mathbf{H}$ & $i-P \mathbf{T}$ & 98 & 72 \\
\hline 7. & $\mathbf{H}$ & $t-\mathrm{Bu}$ & $>99$ & 45 \\
\hline 8. & $\mathbf{H}$ & $\mathbf{P h}$ & $>99$ & $\boldsymbol{\alpha}^{e}$ \\
\hline
\end{tabular}

a) Conversion of 6 is quantitative. Yield decermined by capillary GC. b) The side products are a result of enolate formation. ${ }^{6}$ c) E.e. of (S)-enantiomer detemined by capillary $G C$ with a chiral column. d) Determined by ${ }^{13} \mathrm{C}$ NMR of the corresponding ketal with $(R, R)-(-)-2,3-$ butanediol. e) Determined by optical rotation. 
(1) Yarition of vara substiment $\mathrm{X}$. With either an electron-withdrawing substituent, i.e. $\mathrm{X}=\mathrm{Cl}$ (entry 2), or an electron-donating substituent $(X=M e$ (entry 4$)$ and OMe (entry 5)) the chemoselectivities remain more than $99 \%$ to the 1,4-addition products and the e.e.'s of 69\% (entry 2), 64\% (entry 4) and 56\% (entry 5) point to a small effect of the para-substituent $X$. An exception is $X=C N$ (entry 1 ) in which both the chemo- and enantioselectivity are very low. These data indicate that the anchoring of the double bond to copper ${ }^{8}$ is probably more important for the enantioselectivity than for the chemoselectivity of these Michael addition reactions.

(ii) Yariation of $R^{1}$ on the carbonyl group: Entries 3, 6, and $7\left(R^{1}=H, i-\operatorname{Pr}, t-B u\right.$, respectively) show that chemoselectivity is not affected by steric bulk at this position, though the larger $R^{1}$ groups do lead to noticeably lower enantioselectivity. In contrast the use of $R^{1}=P h$ (entry 8), which also results in a high chemoselectivity, gives the corresponding 1,4 product with an e.c. of $0 \%$. From this one can conclude that the electronic effects of the $R^{1}$ group on the bonding of the enone's alkene and $\mathrm{C}=\mathrm{O}$ functionalities to the $\mathrm{Cu}-\mathrm{S}-\mathrm{Mg}$ motif in $\mathrm{I}$ are probably more important than the steric effects.

The results of this report show the excellent applicability of arenethiolatocopper(n) catalysts 3 in Michael addition reactions. Current research is directed not only to expanding the scope of our catalytic system by employing other chiral arenethiolatocopper(I) catalysts and other substrates such as cyclic enones, ${ }^{9}$ but also to determining kinetic effects on the reaction course and enantioselectivity by means of competition experiments.

Acknowledgement: This work was supported by the Netherlands Foundation of Chemical Research (SON) with financial aid from the Netherlands Organization for Scientific Research (NWO).

\section{References and Notes:}

1. a) Dieter, R. K.; Tokles, M.J. Am. Chem. Soc., 1987, 109, 2040. b) Corey, E. J,; Naef, R.; Hanson, F. J.J. Am. Chem. Sac. 1986, 108, 7114, c) Rossiter, B. E.; Eguchi, M. Tetr. Lett. 1990, 31, 965. d) Bertz, S. H.; Dabbagh, O.; Sundararajan, G. J. Org. Chem. 1986, 51, 4953, e) Alexakis, A.; Mutti, S.; Normant, J. F. J. Am. Chem. Soc. 1991, I13. 6332.

2. a) Lippard, S. Organometallies 1991, 3178. b) Ahn, K. H,; Klassen, R. B.; Lippard, S. J, Organometallics 1990, 9, 3178. b) Tanaka, K.; Matsui, J,; Suauki, H.; Watanabe, A. J, Chem. Soc. Perkin Trans. 1 1992, 1193.

3. a) Lambert, F.; Knotter, D. M.; Janssen, M. D.; van Klaveren, M.; Boersma, J.; van Koten, G. Tetr. Asymmetry 199 1, 2. 1097. b) Knotier. D. M.; Grove, D. M.; Smeets, W. J. J.; Spek, A. L.; van Koten, G. J. Am. Chem. Soc. 1992, 114, 3400. c) van Klaveren, M.; Grove, D. M.; van Koten, G. to be published, d) van Koten, G. Pure and Appl. Chem. 1994, in press. e) Janssen, M. D.; Donkervoort, J. G.; Spek, A. L.; Grove, D. M., van Koten, G. to be pubtished. $\mathrm{O}$ van Koten, G. Proceedings of the third symposium in Wurzburg (Vieweg) 1991.

4. Haubrich, A.; van Klavenen, M.; van Koten, G.; Handke, G.; Krause. N. I. Org. Chem. 1993, $58,5849$.

5. van Klaveren, M.; Persson, E. S. M.; Grove, D. M.; Bzckvall, J. E.; van Koten, G. Tetr. Leti. 1994 , in press.

6. Characterization of the dimeric and trimeric enolate side products includes $\mathrm{X}$-ray structure determination: van Klaveren, $\mathrm{M}$; Lambert, F.; Grove, D. M.; van Koten, G. 10 be publtshed.

7. a) Corey, E. I.; Boaz, N. W. Tetr. Lett. 1985, 26, 6015 and 6019, b) Alexakis, A.; Berla, J.; Besace, Y.Tetr Lett. 1986, 27, 1047. c) Johnson, C. R.; Marren, T. J. Tetr. Lett. 1987, 28, 27. d) Matsuzawa, S.; Horiguschi, Y.; Nakamura, E.; Kuwajima, I. Tetrahedron 1989, 45, 349. e) Nakamura, E. Synlett 1991, 539.

8. Ullenius, C.; Christensan, B. Pure and Appl. Chem. 1988, 60, 57.

9. Zhou, Q.; Pfaltz, A. Tetr. Lett. 1993, 34, 7725. 